\title{
Deformation of the Geocell Flexible Reinforced Retaining Wall under Earthquake
}

\author{
Yalin Zhu, ${ }^{1,2}$ Kun Tan, ${ }^{1}$ Yin Hong, ${ }^{1}$ Ting Tan, ${ }^{1}$ Manrong Song, ${ }^{1}$ and Yixian Wang $\mathbb{D}^{1,3}$ \\ ${ }^{1}$ College of Civil and Hydraulic Engineering, Hefei University of Technology, Hefei, China \\ ${ }^{2}$ Anhui Key Laboratory of Civil Engineering Structures and Materials, Hefei, China \\ ${ }^{3}$ State Key Laboratory of Explosion Science and Technology, Beijing Institute of Technology, Beijing, China \\ Correspondence should be addressed to Yixian Wang; wangyixian2012@hfut.edu.cn
}

Received 2 July 2020; Revised 24 September 2020; Accepted 29 March 2021; Published 9 April 2021

Academic Editor: Sanjay Nimbalkar

Copyright (C) 2021 Yalin Zhu et al. This is an open access article distributed under the Creative Commons Attribution License, which permits unrestricted use, distribution, and reproduction in any medium, provided the original work is properly cited.

\begin{abstract}
As a new type of reinforced material, geocells are widely used in flexible reinforced retaining wall projects, and a lot of practical experience shows that the geocell retaining wall has a great effect on earthquake resistance, but theoretical research lags behind engineering practice, and the deformation and failure mechanism under earthquake need to be further studied. In this paper, we use the FLAC3D nonlinear, finite-difference method to study the failure mechanism of geocell-reinforced retaining walls under earthquake, to analyze the advantages of the geocell retaining wall in controlling deformation compared with the unreinforced retaining wall and geogrid-reinforced retaining wall, and we try to study the deformation of the reinforced wall by changing the length of the geocell and reinforcement spacing of the geocell. Research indicates the horizontal displacement of the wall edge of the reinforced retaining wall under the earthquake is slightly smaller than that of the center of the wall and the back of the wall. The geocell can effectively reduce the horizontal displacement of the retaining wall, and the effect is better than the geogrid. Increasing the length of the geocell and reducing the spacing of the geocell can effectively reduce the horizontal displacement of the retaining wall, and the effect of displacement controlling at the top of the wall is better than in other positions.
\end{abstract}

\section{Introduction}

The geocell retaining wall is a flexible reinforced retaining wall. It is an artificial reinforced retaining wall that sets the geocell horizontally and fills it with soil as the reinforcement material. As we all know, the excellent tensile strength of the geocell can well compensate the characteristics of high compressive strength but with low tensile strength of the soil, thereby effectively increasing the overall strength of the soil and ensuring the safety and stability of the structure. Geocell is a stretchable three-dimensional net structure that can be folded to reduce space during transportation; during construction, it can be expanded into a net structure and then filled with fillers such as soil, sand, or concrete, and when the filler reaches sufficient strength, the entire geocell will become a large rigid composite structure.

At present, the geocell is widely used in many engineering projects worldwide to deal with uneven settlement, improve pavement performance, slope protection, and retaining wall reinforcement and has achieved good benefits [1]; many related scholars have conducted research on the application of geocells in different fields. Some scholars used the numerical simulation and field test to analyze the reinforcement effect of geocell; Isik and Gurbuz concluded that the pullout capacity of geocell reinforcement in cohesionless soils is limited to the seam peel strength at junctions of longitudinal and transverse of geocell strips [2]; Venkateswarlu et al. found that the lateral spreading of vibrations can be significantly controlled in the presence of geocell reinforcement [3]; Tafreshi and Dawson came to a conclusion that the geocell reinforcement system behaves much stiffer and carries greater loading and settles less than does the equivalent planar reinforcement system from laboratory model tests [4]; Mehrjardi and Motarjemi studied the application of geocell in granular soil and found that geocell can effectively improve the shear strength 
characteristics at the interface of granular soil [5]; some researchers have analyzed the engineering application of geocell; Liu et al. found that geocell can effectively improve the stability of the slope reinforced by antislide piles and proposed that, after the geocells are set up, the pile spacing can be appropriately increased to achieve the purpose of reducing the project cost [6]; Kazemian used the three-dimensional strength reduction method to analyze the stability of the geocell slope under local loads and proposed that the safety factor will improve as the length of the geocell layer increases up to a certain length and ceases to develop afterwards [7]; the performance of geogrid-reinforced retaining structures with various layouts was analyzed by FLAC, and the results show that a wall with a facing angle less than $80^{\circ}$ will significantly reduce the lateral displacement of the wall face [8]; Tafreshi et al. carried out experimental simulation on circular foundations of noncohesive soil reinforced by multilayer geocells and obtained a simplified method for predicting foundation settlement [9]; Liu and Jia conducted a sensitivity analysis on the stability of the geogrid retaining wall and concluded that the internal friction angle of the fill is the most critical factor to ensure the safety and stability of the reinforced retaining wall [10].

However, most of the research studies on geocell-reinforced retaining walls are in the static calculation part at present. There is little research on the deformation of reinforced retaining walls under earthquakes. China is a country with frequent earthquakes, which has a significant influence on the stability of Geotechnical engineering projects [11-15]. Due to the suddenness, complexity, and instantaneity of earthquakes, the safety and stability of retaining walls are often not guaranteed. Large horizontal displacements, vertical settlements, or even complete collapse of retaining walls under earthquakes often result in large economic losses. Seismic damage in major earthquakes shows that most of the unreinforced retaining walls under a strong earthquake have suffered a certain degree of damage, while the seismic damage of geocell-reinforced retaining walls is much less. With the increasing application of reinforced retaining walls in earthquake-prone areas, related theoretical research must closely follow engineering practice and provide theoretical support for practice. Therefore, this paper uses FLAC3D's nonlinear finite difference method to calculate and analyze the dynamic response and deformation characteristics of geocell-reinforced retaining walls under earthquakes and then, by changing the reinforcement length and cell spacing to further explore the dynamic characteristics of geocell-reinforced retaining wall, provide theoretical basis for engineering practice.

\section{Features of Dynamic Computing in FLAC3D}

FLAC3D is geotechnical numerical simulation software with very powerful dynamic analysis capabilities [16-20]. It uses a completely nonlinear analysis method for dynamic calculation analysis. Compared to the equivalent linear method which is more widely used [21,22], the completely nonlinear calculation method used by FLAC3D has the following advantages:
(1) FLAC3D dynamic calculation can well follow any specified nonlinear constitutive model. In addition, the hysteretic characteristics of the soil under dynamic action in the fully nonlinear method are achieved by setting reasonable damping parameters, while the equivalent linear method achieves the hysteresis of the soil by transforming the backbone curve.

(2) Due to the use of nonlinear material laws, the program can naturally cause interference and mixing between waves of different frequencies, making the simulation process more in line with actual conditions, which cannot be achieved by equivalent linear methods.

(3) Because the elastoplastic model is used, the shortcomings of the equivalent linear method that cannot calculate the permanent displacement spontaneously are overcome; in addition, the completely nonlinear method uses a reasonable plastic theory to correctly construct the functional relationship between the plastic strain incremental tensor and the stress tensor.

(4) The completely nonlinear method can not only simulate the propagation of $\mathrm{P}$-waves and S-waves but also consider the effect on soil materials when the two waves are coupled, and the influence of this coupling effect under strong earthquake cannot be ignored. For example, for some friction materials, this coupling effect will reduce the shear strength of the soil by dynamically reducing the normal stress.

Therefore, compared to the widely accepted equivalent linear method, the completely nonlinear method adopted by FLAC3D is more able to reflect the real situation of soil under earthquakes, and the calculation results are more convincing [23].

\section{Numerical Simulation of Geocell-Reinforced Retaining Wall}

3.1. Geometric Model. The calculation model is a staircase retaining wall; the wall height is $4.2 \mathrm{~m}$, with one step per two floors, and the step gradient ratio is $1: 4$; the thickness of the foundation is $6.0 \mathrm{~m}$, and the length is $16.8 \mathrm{~m}$; the length of the geocell is $3.0 \mathrm{~m}$, and the geocell spacing is $0.3 \mathrm{~m}$; the basement depth is $1.2 \mathrm{~m}$, and length is $3.0 \mathrm{~m}$; and the width of the entire model is $3.6 \mathrm{~m}$. The foundation, the soil behind the wall, and the fillings are mainly medium coarse sand. Interface elements are set between the back of the wall and the soil behind the wall, between the bottom of the wall and the basement, and between the basement and the foundation, which are used to simulate the relative sliding between different material surfaces. In order to ensure the accuracy of the calculation results, the grids in the area where the geocell is located are encrypted. The calculation grids are shown in Figure 1.

In terms of boundary condition selection, static boundary conditions are used for static calculations, with full 
constraints on the bottom of the model in three directions, constraints on the front and back sides in the $Y$-direction, and constraints on the left and right sides in the $X$-direction. In the dynamic analysis, free-field boundary conditions are applied, that is, generating two-dimensional planar grids and onedimensional cylinder grids on each side of the model, which is used to simulate free-field motion without a ground structure and to simulate the same effect as an infinite venue.

The geogrid element of FLAC3D is arranged horizontally and vertically in the model to simulate the layout of the geocell. The friction characteristics between the reinforcement and the soil can be simulated by the spring-slider system, which can reasonably solve the problem that there is no structural element of the geocell in FLAC3D. The specific model of the geocell is shown in Figure 2.

3.2. Loads of Earthquake. The calculation loads adopted in this paper mainly include gravity load, $5 \mathrm{kPa}$ overload which is applied on the filling surface, and seismic load. The Kobe seismic wave was used as the seismic load and applied to the bottom of the model in the vertical direction. The Kobe earthquake had a magnitude of 7.2 and caused a major earthquake disaster at the time. Afterwards, the researchers recorded the seismic wave waveform and used it extensively in subsequent scientific research. This paper investigates the deformation of geocell reinforced retaining walls under earthquakes. Therefore, the representative Kobe seismic wave in current seismic research is selected as the seismic wave during calculation.

Because the seismic frequency is in the range of 1 to $5 \mathrm{~Hz}$, the SeismoSignal seismic wave processing software is used to filter out the part of the seismic wave with a frequency less than $1 \mathrm{~Hz}$ or greater than $5 \mathrm{~Hz}$. The filtered seismic wave waveform is shown in Figure 3.

3.3. Mechanical Damping. The main causes of damping are friction between materials, possible slippage between contact surfaces, and hysteretic energy dissipation of local yielding of structural materials. In order to make the dynamic equations converge faster, more damping is often used in quasistatic calculations to save calculation time; for damping in dynamic calculation, you need to reproduce the damping of the natural system under dynamic load conditions in numerical analysis and simulation. Initially, Rayleigh damping was set in the structural and elastomer dynamic analysis to reduce the natural vibration amplitude of the system. The following formulas are commonly used in calculations to show the relationship between the damping matrix $C$, the mass matrix $M$, and the stiffness matrix $K$ in the dynamic equation [24]:

$$
C=\alpha M+\beta K
$$

In the abovementioned formula, $\alpha$ represents a damping constant proportional to mass and $\beta$ represents a damping constant proportional to stiffness.

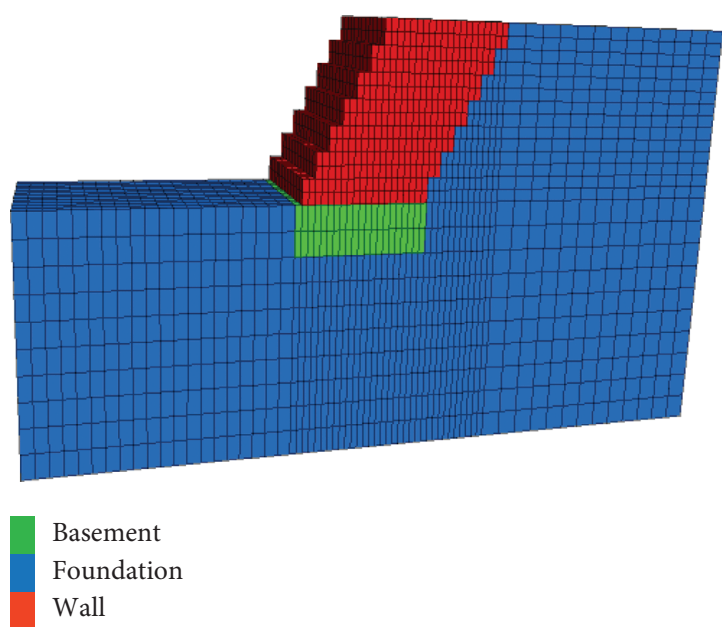

Figure 1: Elements of the calculation model.

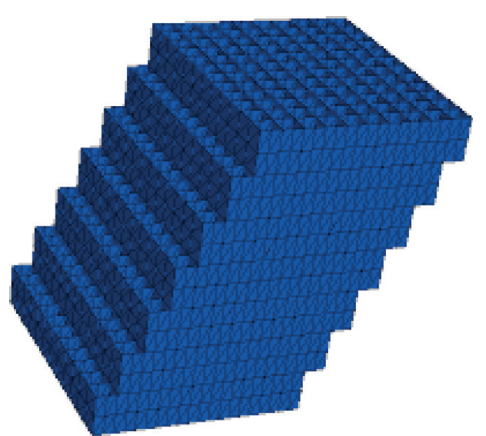

FIgURE 2: Layout of the geocell.

The two parameters that need to be determined for Rayleigh damping are the minimum center frequency and the minimum critical damping ratio, which can be calculated by the following formula:

$$
\begin{gathered}
\xi_{\min }=(\alpha \bullet \beta)^{1 / 2}, \\
\omega_{\min }=\left(\frac{\alpha}{\beta}\right)^{1 / 2} .
\end{gathered}
$$

In the abovementioned formula, $\xi_{\min }$ represents the minimum critical damping ratio and $\omega_{\min }$ represents the minimum center frequency.

For geotechnical materials, the critical damping ratio is generally in the range of $2 \%-5 \%$, which is 0.05 in this paper; for simpler models, the natural frequency of the structure can generally be used as the minimum center frequency of Rayleigh damping. In this paper, the boundary conditions introduced above are set on the calculation model, without setting damping, applying gravity, solving 5000 steps, to make the model oscillate. Then, the displacement response is extracted at each calculation step at the bottom midpoint of the retaining wall for analysis, an oscillation period is found, and the reciprocal is taken to get the natural frequency of the model. It is calculated that the oscillation period of the 


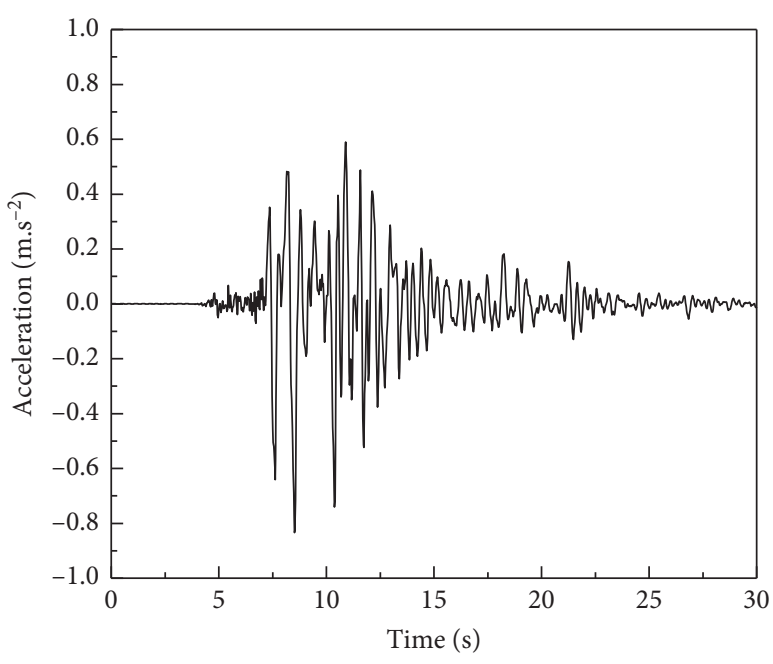

Figure 3: Seismic waveform.

model is $0.1901 \mathrm{~s}$, and the natural frequency of the system, that is, the minimum center frequency, is $5.26 \mathrm{~Hz}$.

3.4. Material Parameters. The Mohr-Coulomb model shows good applicability in many practical problems of geotechnical engineering. Because its material parameters are easy to obtain, it is widely used in numerical simulation of geotechnical engineering. The Mohr-Coulomb model is used for the basement part, the geocell interior filling, and the foundation and the filling behind the wall. The parameters required for the model are determined by geotechnical tests. See Table 1 for detailed parameters.

To simulate the interaction between the retaining wall and the soil behind the wall, between the cell and the fill, and between the basement and the fill, the interface at the contact surfaces is set between the retaining wall and the soil behind the wall and at the contact surfaces between the foundation and the cell-filling soil. Since the geogrid element in FLAC3D is a structural surface element, there is no need to establish an interface between the geocell and the filling. The relevant parameters at the interface between the geocell and the soil are shown in Table 2.

The interface parameters at the interface between the retaining wall and the soil behind the wall and at the interface between the basement and the filling mainly include cohesion, friction angle, normal stiffness, and tangential stiffness. Chen and $\mathrm{Xu}$ [25] carried out simulation experiments on a large number of engineering examples and found that the cohesive force and friction angle at the contact surface are about $0.5-0.8$ times of the adjacent soil layer at the contact surface. The values of normal stiffness and shear stiffness can be calculated by using the following formula:

$$
k_{n}=k_{s}=10 \max \left[\frac{(K+(4 / 3) G)}{\Delta z_{\min }}\right] \text {. }
$$

In the abovementioned formula, $K$ is the bulk modulus, $G$ is the shear modulus, and $\Delta z_{\min }$ is the minimum size of the normal connection area of the contact surface.
According to the calculation, the specific parameters of the interface are shown in Table 3.

\section{Results and Analysis of Calculation}

4.1. Analysis of the Reinforcement Effect of the Geocell on Retaining Walls under Earthquake. In order to analyze the calculation results more simply, a total of 45 monitoring points were arranged in the retaining wall model to record the deformation of different parts of the retaining wall. The positions of the monitoring points are selected on the surface of the corner points in the width direction of the retaining wall. The specific locations of the points are shown in Figure 4 .

4.1.1. Deformation Analysis of the Geocell Retaining Wall at Some Point. In order to show the reinforcement effect of the geocell on the retaining wall more intuitively, this paper selects the overall deformation of the retaining wall without and with the geocell at a representative time. This paper analyzes the displacement of two retaining walls over time under earthquakes. Because the geocell has a better reinforcement effect at the top corners of the wall [26] and the length of the article is limited, in this paper, the displacement at monitoring point $\mathrm{A}$ is taken every $0.1 \mathrm{~s}$, and the displacement-time relationship is established for analysis.

It can be seen from Figure 5 that the trend of the displacement-time-history curve of the retaining wall with or without the geocell is similar, but the displacement amplitude of the retaining wall with the geocell are much smaller than those of the unreinforced retaining wall, and the average amplitudes of displacement-time-history curves of the two types of retaining walls were $9.75 \mathrm{~cm}$ and $2.0 \mathrm{~cm}$, respectively. The maximum displacement of the geocell retaining wall occurred at $18.4 \mathrm{~s}$, and at this moment, the horizontal displacements of the geocell-free retaining wall and the geocell retaining wall were $16.38 \mathrm{~cm}$ and $4.65 \mathrm{~cm}$, respectively; the maximum displacement of the geocell retaining wall occurred at $13.2 \mathrm{~s}$, which was $4.73 \mathrm{~cm}$. At this time, the displacement of the geocell-free retaining wall was $12.9 \mathrm{~cm}$. Therefore, this paper chooses the time when the displacement of the two types of retaining walls is relatively large, that is, at the $18.4 \mathrm{~s}$, for further analysis.

Figures 6 and 7, respectively, show the deformation of the unreinforced retaining wall and geocell flexible retaining wall at $18.4 \mathrm{~s}$ (magnification 5 times). It can be seen that the deformation of the retaining wall mainly occurs at the side of the wall, and the horizontal displacement there shows a tendency of "inner concave," that is, the horizontal displacement at each corner point in the $Y$-direction is greater than in other parts. The top surface of the wall back has a slight upward tendency. The back of the wall and the soil behind the wall are separated to a certain extent. The other parts such as the soil behind the wall and the foundation are not affected by the earthquake to a great extent.

The overall deformation trends of the two retaining walls under earthquakes are generally similar, but the overall deformation degrees are quite different. The horizontal 
TABLe 1: Calculation parameters of soil.

\begin{tabular}{lccccc}
\hline Material & Density $\left(\mathrm{kg} \cdot \mathrm{m}^{-3}\right)$ & Cohesion $(\mathrm{kPa})$ & Friction $\left(^{\circ}\right)$ & Bulk modulus $(\mathrm{MPa})$ & Shear modulus $(\mathrm{MPa})$ \\
\hline Wall & 2228 & 40 & 30 & 41.7 & 19.2 \\
Basement & 2360 & 70 & 40 & 36.1 & 27.1 \\
Foundation & 1800 & 30 & 25 & 16.6 & 11.1 \\
\hline
\end{tabular}

TABLE 2: Related parameters of the geocell.

\begin{tabular}{lcccccc}
\hline & & Geocell & & \multicolumn{2}{c}{ Coupling parameters of the geocell-soil interface } \\
Parameters & Density $\left(\mathrm{kg} \cdot \mathrm{m}^{-3}\right)$ & Thickness $(\mathrm{mm})$ & Poisson's ratio & Stiffness $(\mathrm{MPa})$ & Cohesion $(\mathrm{MPa})$ & Friction $\left({ }^{\circ}\right)$ \\
\hline Value & 1000 & 5 & 0.33 & 2 & 2 & 29 \\
\hline
\end{tabular}

TABLE 3: Material parameters of the interface.

\begin{tabular}{|c|c|c|c|c|}
\hline & Shear stiffness $(\mathrm{MPa})$ & Normal stiffness $(\mathrm{MPa})$ & Cohesion $(\mathrm{kPa})$ & Friction $\left({ }^{\circ}\right)$ \\
\hline Between the wall and the soil behind the wall & $4.48 \times 10^{3}$ & $4.48 \times 10^{3}$ & 56 & 26 \\
\hline Between the wall and the basement & $4.67 \times 10^{3}$ & $4.67 \times 10^{3}$ & 56 & 26 \\
\hline
\end{tabular}

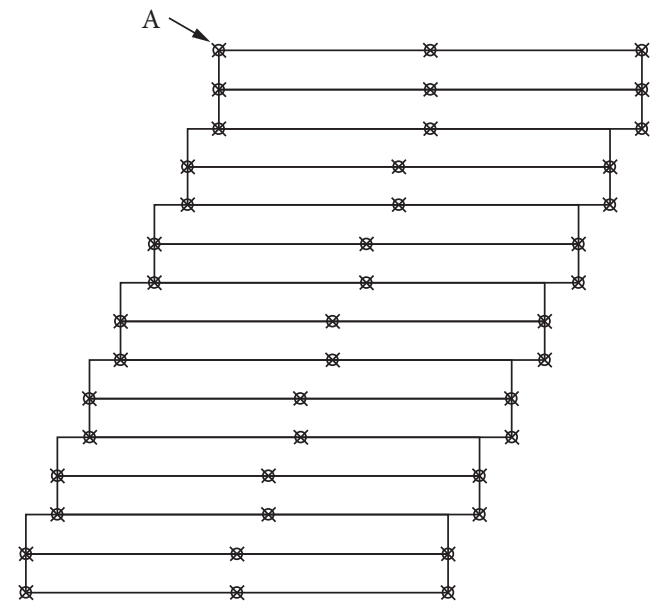

FIGURE 4: Layout of the monitoring point.

displacement of the unreinforced retaining wall at the top corner of the wall shown in Figure 6 is $16.38 \mathrm{~cm}$, and serious damage has occurred. At this time, the horizontal displacement of the geocell retaining wall is only $4.65 \mathrm{~cm}$, which shows that the reinforcement effect is obvious. It can be seen that the reinforcement effect of the geocell as a reinforced material on the retaining wall is very significant.

4.1.2. Analysis of the Reinforcement Effect of the Geocell on Different Parts of Retaining Walls. The control effect of the geogrid on the overall horizontal displacement of the retaining wall at $18.4 \mathrm{~s}$ is mentioned above. This section examines the displacements of the two types of retaining walls in different parts of the wall at their most dangerous moments (the moment when the horizontal displacement of the retaining wall reaches its maximum value. For a retaining wall without the geocell, this moment is $18.4 \mathrm{~s}$, and for a retaining wall with the geocell, it is $13.2 \mathrm{~s}$ during the entire earthquake, and the reinforcement effects of the geocell at different parts of the retaining wall are studied.

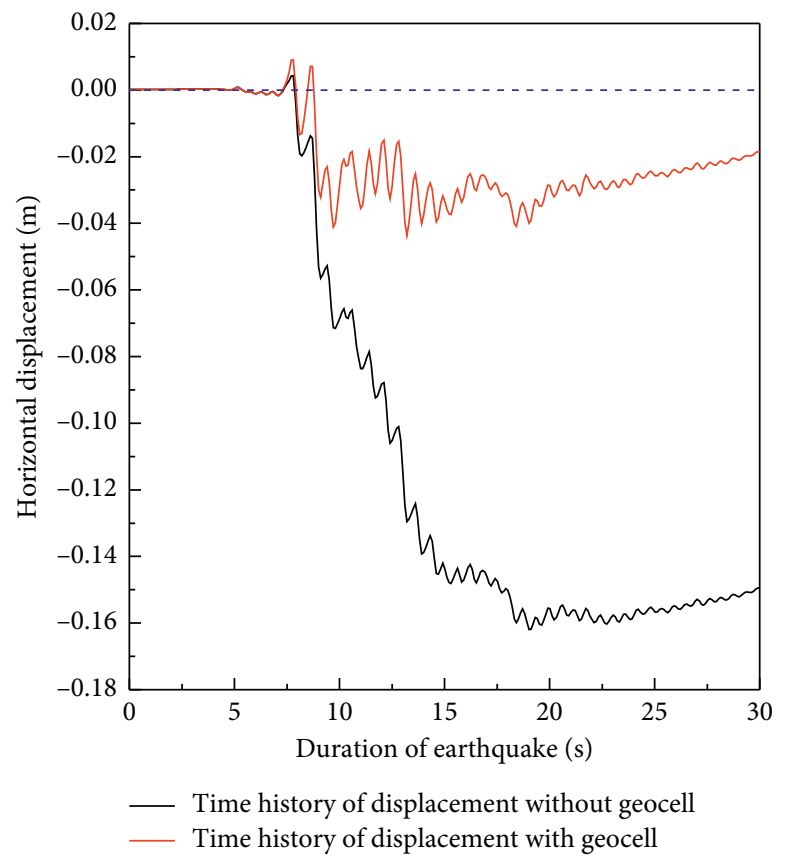

FIgURE 5: Displacement-time-history of monitoring point A.

The horizontal displacement of each part of the retaining wall with or without the geocell is shown in Figure 8. The horizontal displacement of the side of the stepped retaining wall under earthquakes is smaller than that of the other parts. The distribution of wall displacement along the wall height of the two types of retaining walls generally follows the same trend of decreasing first and then increasing, but the degree of displacement is different; for the retaining wall without the geocell, the average horizontal displacement along the side of the wall is $6.20 \mathrm{~cm}$, and the displacement increases along the wall height after the minimum value at the wall height of $0.6 \mathrm{~m}$. The horizontal displacement increases faster after the wall height exceeds $3.6 \mathrm{~m}$ and reached the maximum at the top of the wall, $16.38 \mathrm{~cm}$, which has not 


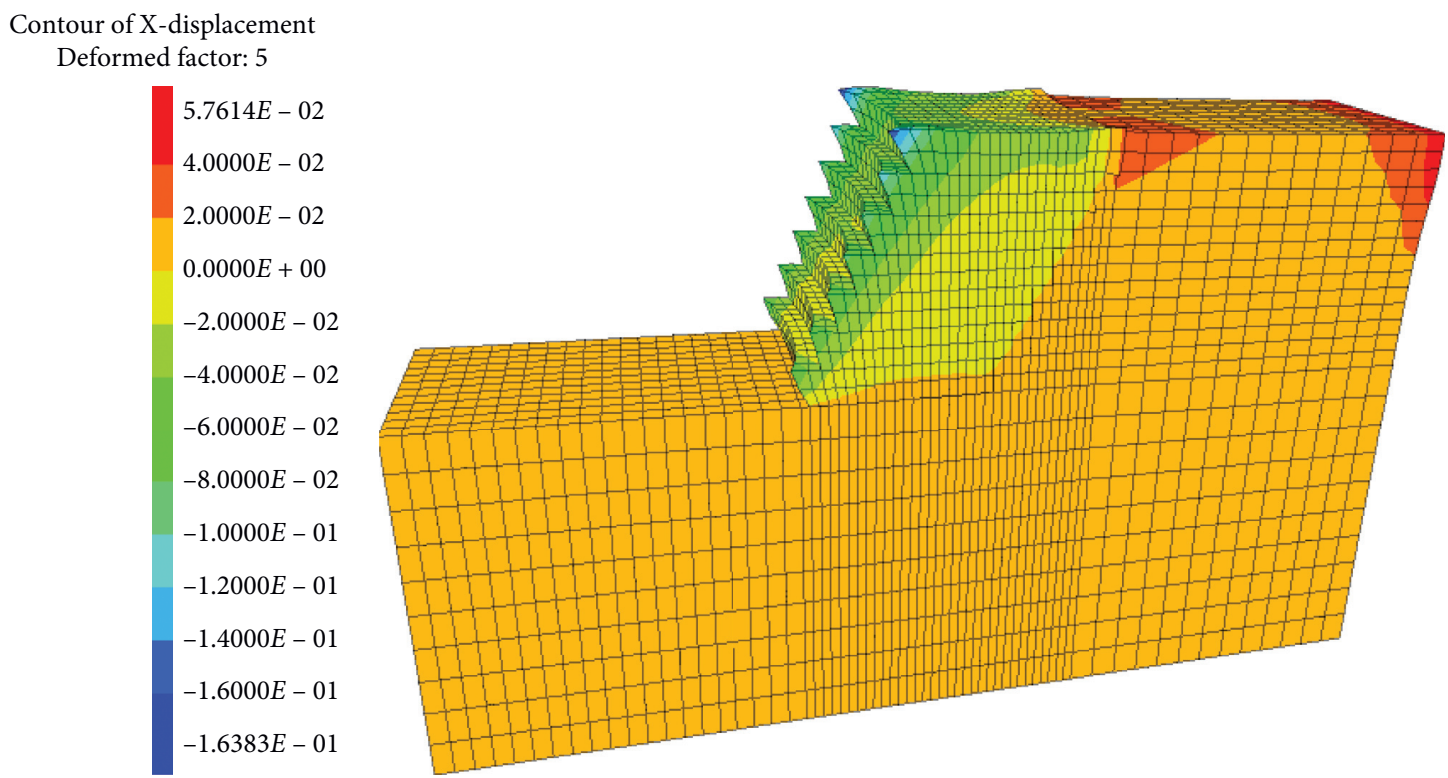

Figure 6: Displacement of the unreinforced retaining wall at $18.4 \mathrm{~s}$.

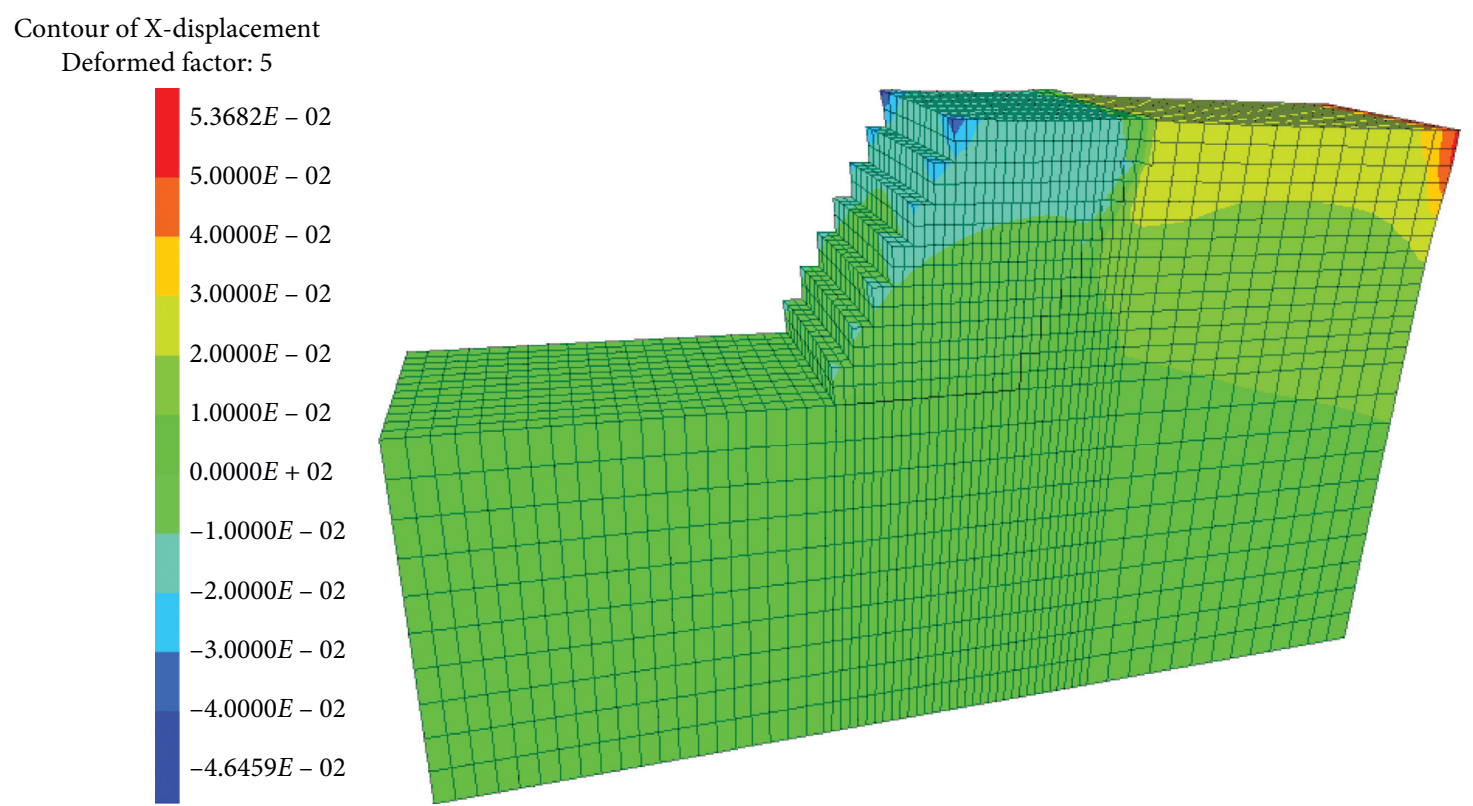

Figure 7: Displacement of the geocell flexible retaining wall at $18.4 \mathrm{~s}$.

met the requirements of the minimum horizontal displacement of the retaining wall; for the reinforced retaining wall of the geocell, the average horizontal displacement along the side of the wall is $2.84 \mathrm{~cm}$. When the horizontal displacement reaches a minimum value at the height of $1.8 \mathrm{~m}$, the growth rate along the height of the wall slows down significantly. The maximum value of horizontal displacement at the wall occurs at the top of the wall, which is $4.73 \mathrm{~cm}$. Compared with the maximum displacement of the retaining wall without the geocell, the maximum displacement has been reduced by $71.1 \%$. It can be seen that the geocell has a significant effect on the retaining wall. In addition, the horizontal displacement in the middle of the wall and the back of the wall is smaller than the side of the wall, and it is more evenly distributed along the wall height; Figure 8 shows that the geocell can indeed reduce the horizontal displacement of the middle wall and the back of the retaining wall, but the effect is not as good as that for the horizontal displacement of the side of the wall.

The vertical settlement of each part of the retaining wall with or without the geocell is shown in Figure 9. It can be seen that all of the vertical settlements of the wall edge, the middle of the wall, and the back of the wall generally show a gradually increasing trend along the wall height. The maximum vertical settlement of the retaining wall occurs at the top surface of the wall. The maximum vertical 


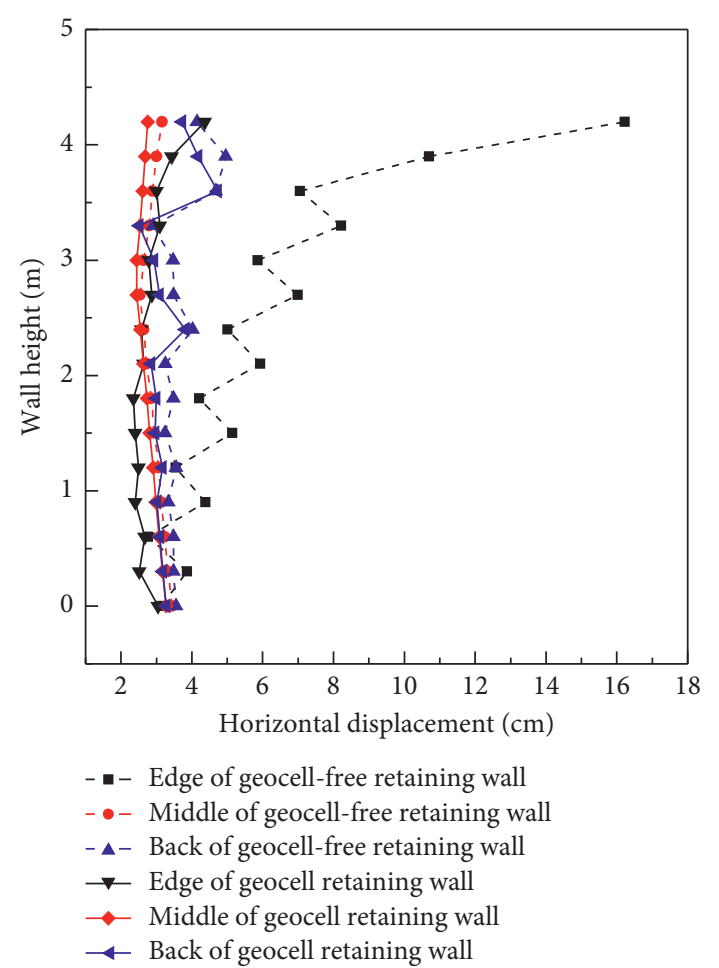

FIgURE 8: Horizontal displacement of the retaining wall.

displacements of the retaining wall with or without the geocell are $2.70 \mathrm{~cm}$ and $0.401 \mathrm{~cm}$, respectively, the reduction is $85 \%$, and the reinforcement effect is obvious. When no geocell is added, the vertical settlement at the side of the wall and the upper part of the back of the wall is larger, and it grows faster along the wall height; with the addition of the geocell, the maximum vertical settlement reductions of the side of the wall, the middle of the wall, and the back of the wall were $85 \%, 40.1 \%$, and $30 \%$, respectively. The vertical settlement of the retaining wall was significantly controlled. It is easy to see from the figure that the control effect of the geocell on the vertical settlement of the retaining wall mainly occurs at the upper part of the wall, and it also has a certain control effect on the vertical settlement of the bottom of the wall, but it is not obvious in comparison; in addition, the reinforcement effect of the geocell is mainly reflected at the side of the wall and the back of the wall, but the effect of controlling vertical settlement in the middle of the wall is not obvious enough.

4.1.3. Analysis of the Reinforcement Effect of the Geocell Compared to the Geogrid. This section also introduces a geogrid retaining wall and further validates the reinforcement effect of the geocell on the retaining wall by comparing the dynamic response of the geocell-free retaining wall, the geocell retaining wall, and the geogrid retaining wall under earthquake. When the geogrid is added to the geocell-free retaining wall model, the geogrid material properties are the same as those of the geocell but with the different layout methods: layered horizontally along the height of the wall, a

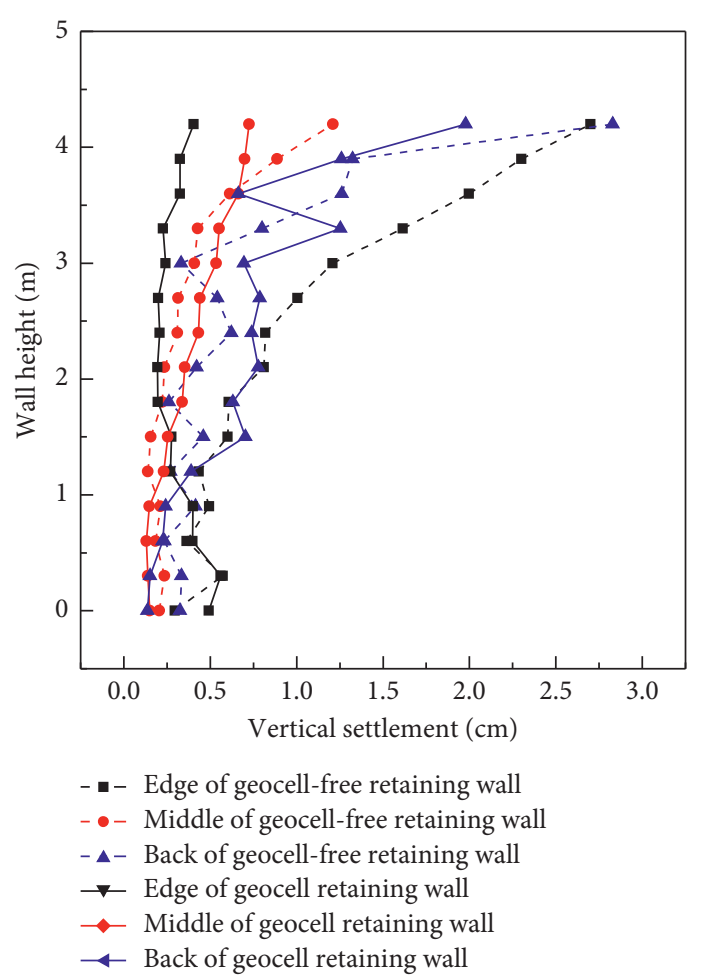

Figure 9: Vertical displacement of the retaining wall.

layer of geogrid is arranged every $0.3 \mathrm{~m}$, and the length is $3.0 \mathrm{~m}$. Figure 10 shows the layout of the geogrid.

Figure 11 shows the horizontal displacement of the geogrid-free retaining wall, the geocell retaining wall, and the geogrid retaining wall at the most dangerous moment of the earthquake. It can be seen that the overall trend of the horizontal displacement of the three types of retaining walls is the same, generally showing a gradually increasing trend along the wall height. It can be clearly seen in the figure that the geocell retaining wall has a better control of horizontal displacement than the geogrid retaining wall and the unreinforced retaining wall. The horizontal displacements of the three types of retaining walls are roughly the same at the bottom of the wall, but the horizontal displacements are quite different at the top of the wall. Compared to the unreinforced retaining wall, the horizontal displacements of the geocell retaining wall and the geogrid retaining wall are reduced by $11.857 \mathrm{~cm}$ and $9.644 \mathrm{~cm}$, respectively, and the reductions were $73.1 \%$ and $59.5 \%$. The analysis results on the one hand show the superiority of the geocell compared to the geogrid in terms of earthquake resistance and, on the other hand, verify the correctness of the numerical simulation process.

The vertical settlement along the wall height of the three types of retaining walls is shown in Figure 12, and it can be seen that the geocell and the geogrid have a certain control effect on the vertical settlement of the retaining wall. The vertical settlement of the side of the unreinforced retaining wall gradually increases along the height of the wall, and the increase is greater at a height of $3.0 \mathrm{~m}$ or higher; the vertical settlement curve along the wall height of the geocell 


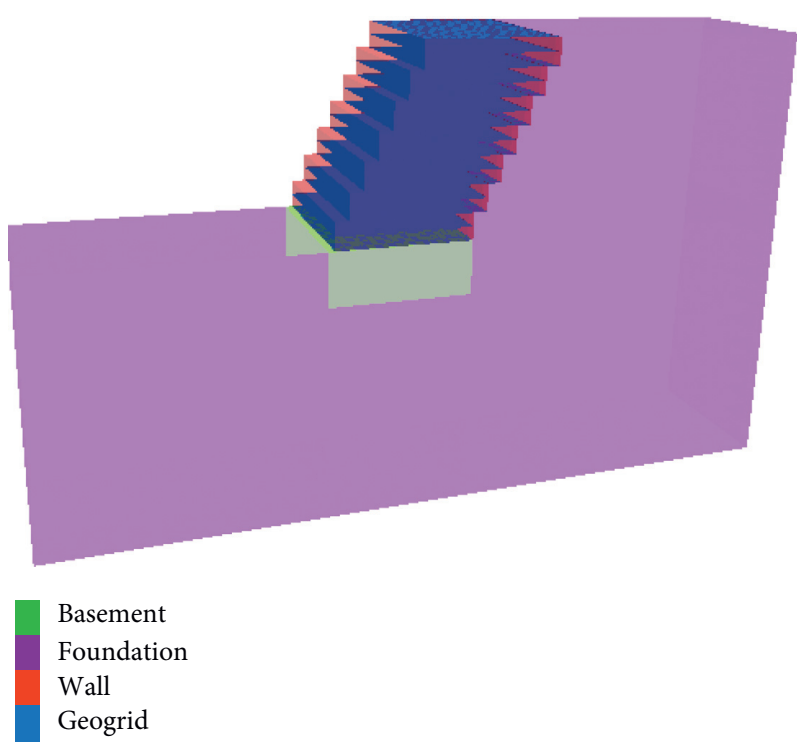

Figure 10: Layout of the geogrid.

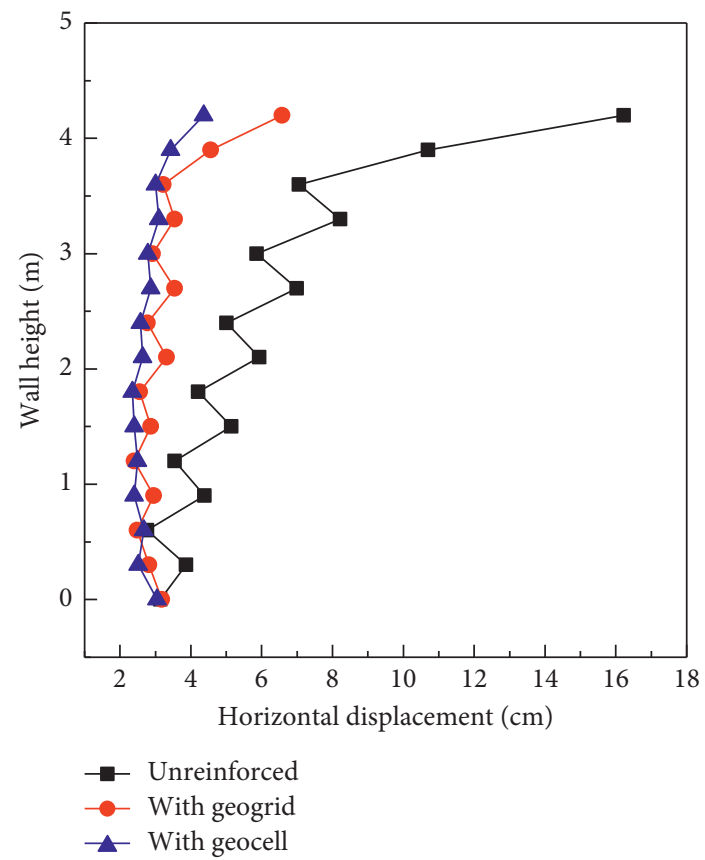

FIGURE 11: Horizontal displacement curve of three retaining wall edges.

retaining wall and the geogrid retaining wall showed a trend of increasing first and then decreasing, but the vertical settlement along the wall of the geocell retaining wall is more evenly distributed along the wall height; the average vertical settlement of the unreinforced retaining wall is $1.055 \mathrm{~cm}$, and the average settlement of the geogrid retaining wall and the geocell retaining wall is $0.469 \mathrm{~cm}$ and $0.314 \mathrm{~cm}$, respectively, and the settlement decreases are $55.54 \%$ and $70.23 \%$. It can be seen that the geocell retaining wall has a better control of vertical settlement than the geogrid retaining wall. The control effect is mainly reflected in the upper part of the wall, and the reinforcement effect at the top of the wall is the best, with a reduction of $84.99 \%$. At the same height of the wall, the reduction of vertical settlement by the geogrid is only $47.59 \%$; the geocell has a poor control of vertical settlement at the bottom of the wall, and the vertical settlement has a small increase compared to the unreinforced retaining wall.

4.2. Influence of Geocell Length on Retaining Walls. In order to further investigate the horizontal displacement of the geocell-reinforced retaining wall at the most dangerous moment of the earthquake, under the condition that other factors remain unchanged, the influence of the reinforcement length on the deformation behavior of the geocell retaining wall is discussed by changing the reinforcement length.

Figure 13 shows the horizontal displacement of the retaining wall when the reinforced lengths are $2.4 \mathrm{~m}, 3.0 \mathrm{~m}$, $3.6 \mathrm{~m}, 4.2 \mathrm{~m}$, and $4.8 \mathrm{~m}$, respectively. It can be seen from the figure that as the reinforcement length gradually increases, the effect of controlling the horizontal displacement of the wall is better. This is due to the small elastic modulus of the soil filling in the cell and the large difference with the elastic modulus of the geocell reinforcement. The displacement values generated when the earthquake load is shared as a whole are inconsistent, leading to greater friction between the cell layer and the soil filling. Therefore, as the reinforcement length increases, the contact surface area of the two materials will also increase, resulting in further increase in friction. In this way, the horizontal displacement of the reinforced retaining wall under earthquakes will be effectively reduced. When the reinforcement length is different, the trend of the horizontal displacement of the wall edge along the wall height is generally the same, and the horizontal displacements of the two types of retaining walls show a trend of decreasing first and then increasing along the wall height. It is not difficult to find that the increase of the reinforcement length will cause the minimum value of the horizontal displacement curve to gradually move up. The increase of the reinforcement length has a certain control effect on the horizontal displacement of the wall edge, but it has the greatest effect on the horizontal displacement of the top of the wall side, and the horizontal displacement of the $4.2 \mathrm{~m}$ geocell retaining wall is reduced by $4.645 \mathrm{~cm}$ compared to the $2.4 \mathrm{~m}$ geocell retaining wall, a decrease of $60.8 \%$; However, when the reinforcement length is further increased to $4.8 \mathrm{~m}$, although the horizontal displacement is reduced to a certain extent, the decrease is not obvious. It can be seen that there is a limit to the length of reinforcement, and beyond this limit, increasing the reinforcement length will not significantly improve the reinforcement effect.

4.3. Influence of Geocell Spacing on Retaining Walls. In order to investigate the horizontal displacement of the geocellreinforced retaining wall at the most dangerous moment of the earthquake at different geocell spacings, five kinds of reinforced retaining walls with different geocell spacings of $0.15 \mathrm{~m}, 0.3 \mathrm{~m}, 0.6 \mathrm{~m}, 0.9 \mathrm{~m}$, and $1.2 \mathrm{~m}$ were selected, the reinforcement length is selected to be $3.6 \mathrm{~m}$, and the other 


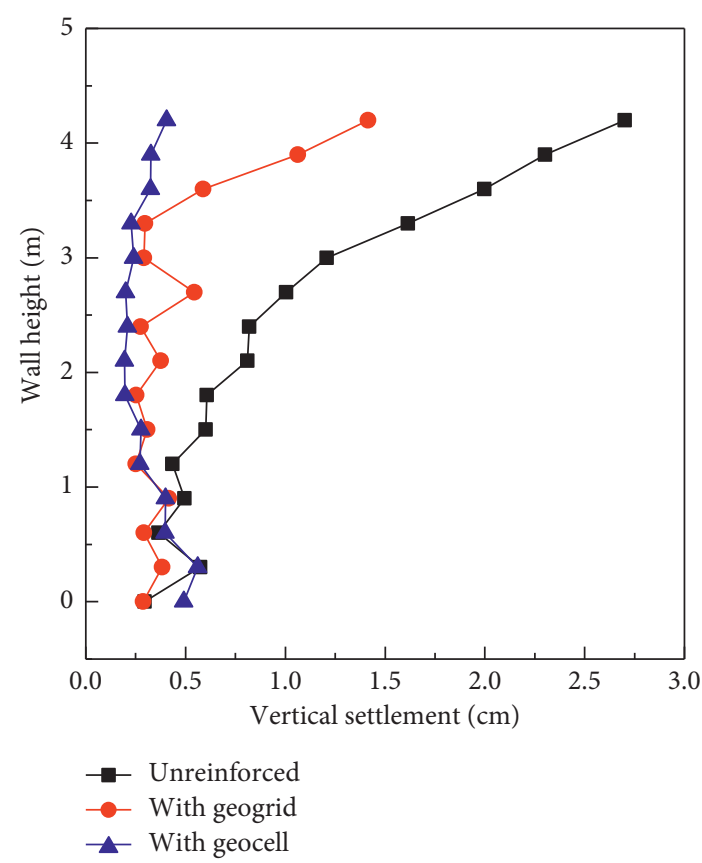

FIgURE 12: Vertical displacement curves of three retaining wall edges.

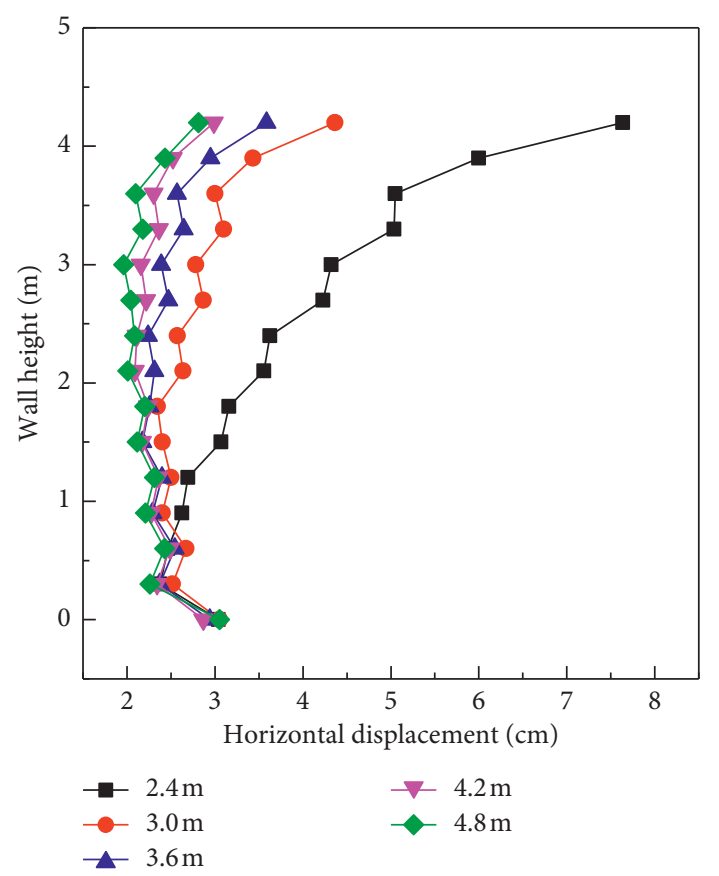

FIGURE 13: Horizontal displacement of the retaining wall under different geocell lengths.

conditions are the same as mentioned above. It can be seen from Figure 14 that the effect of reducing the geocell spacing is less obvious than the effect of increasing the geocell length. The overall trend of the curve is roughly the same. The horizontal displacement along the wall height continues to decrease and reaches an extremum and then increases, and the effect of the geocell spacing at the bottom of the wall is

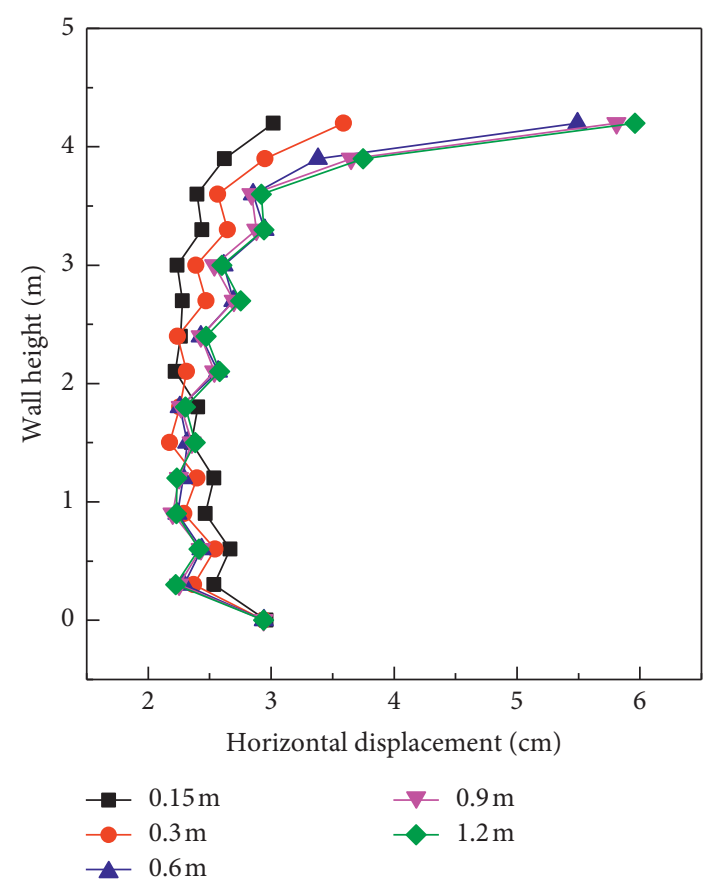

FIGURE 14: Horizontal displacement of the retaining wall under different geocell spacings.

almost negligible. When the geocell spacing is large, a small decrease in geocell spacing has little effect on the horizontal displacement of the retaining wall; however, when the geocell spacing is reduced to $0.6 \mathrm{~m}$, further reducing the geocell spacing can effectively reduce the horizontal displacement at the top of the reinforced retaining wall. The control effect of the geocell spacing on the horizontal displacement is mainly reflected at the top of the wall; when $0.15 \mathrm{~m}$ and $1.2 \mathrm{~m}$ are spaced, the displacement there is $3.018 \mathrm{~cm}$ and $5.958 \mathrm{~cm}$, respectively. It is easy to obtain that the displacement of the top of the wall can decrease by $49.36 \%$ by reducing the spacing of the cells, and the control effect is obvious. In addition, it can be seen that the horizontal displacement of the lower part of the retaining wall increases slightly as the geocell spacing decreases, but the effect is not significant.

\section{Conclusions}

This paper uses the FLAC3D nonlinear finite difference method to calculate and analyze the horizontal displacement of a stepped geocell-reinforced retaining wall under earthquake. By comparing with the unreinforced retaining wall and the geogrid-reinforced retaining wall, the reinforcement effect of the geocell as a reinforced material on the retaining wall is studied. The horizontal displacement of the stepped retaining wall under earthquake is studied by changing the length and spacing of the geocell. The following conclusions were reached:

(1) The horizontal displacement of the retaining wall and the vertical settlement of the upper part of the retaining wall can be well controlled by setting up the 
geocell, and the "inner concave" effect of the retaining wall along the wall edge can be significantly controlled.

(2) Since the geogrid cell has the best control of horizontal displacement of the retaining wall edge, the horizontal displacement of the unreinforced retaining wall edge under the earthquake is larger than that of the middle and the back of the retaining wall, but for geocell retaining walls, the horizontal displacement of the wall edge is slightly smaller than the other two.

(3) The reinforcement effect of the geocell and the geogrid on the retaining wall is obvious, but the geocell has better control of the horizontal displacement of the retaining wall under the earthquake.

(4) The increase of the length of the geocell has the best effect on the control of horizontal displacement at the top of the wall. There is a limit to the length of the reinforcement. After the limit is exceeded, the effect of increasing the length of the reinforcement on the horizontal displacement is not significant.

(5) The effect of the change in the spacing of the geocell on the horizontal displacement is mainly reflected in the top position of the wall, and it has little impact at the bottom of the wall. When the geocell spacing is large, slightly reducing the geocell spacing has little effect on reducing the horizontal displacement of the retaining wall. When it is reduced to $0.6 \mathrm{~m}$, the control effect of further reducing the geocell spacing is obvious.

\section{Data Availability}

All data generated or analyzed during this study are included in this article.

\section{Conflicts of Interest}

The authors declare no conflicts of interest.

\section{Acknowledgments}

This project was supported by the Natural Science Foundation of China (51409076, 51774107; and 42077249), the Opening Project of State Key Laboratory of Explosion Science and Technology, Beijing Institute of Technology (KFJJ21-03Z), and the Fundamental Research Funds for the Central Universities of China (PA2019GDPK0088).

\section{References}

[1] T. H. Liu, "Deformation analysis of geocell reinforced wall," in Proceedings of the National Academic Forum on Civil Engineering Postgraduates, 2010.

[2] A. Isik and A. Gurbuz, "Pullout behavior of geocell reinforcement in cohesionless soils," Geotextiles and Geomembranes, vol. 48, no. 1, pp. 71-81, 2020.
[3] H. Venkateswarlu, K. N. Ujjawal, and A. Hegde, "Laboratory and numerical investigation of machine foundations reinforced with geogrids and geocells," Geotextiles and Geomembranes, vol. 46, no. 6, pp. 882-896, 2018.

[4] S. N. M. Tafreshi and A. R. Dawson, "Comparison of bearing capacity of a strip footing on sand with geocell and with planar forms of geotextile reinforcement," Geotextiles and Geomembranes, vol. 28, no. 1, pp. 72-84, 2010.

[5] G. T. Mehrjardi and F. Motarjemi, "Interfacial properties of Geocell-reinforced granular soils," Geotextiles and Geomembranes, vol. 46, no. 4, pp. 384-395, 2018.

[6] D. Liu, X. Yang, and Z. Mao, "Research on the effect of geocell in slope reinforcement using anti-slide pile with geocell," in Proceedings of the Fourth International Conference on Digital Manufacturing \& Automation, IEEE, Qingdao, China, June 2013.

[7] A. Kazemian, "Three-dimensional stability of locally loaded geocell-reinforced slopes by strength reduction method," Geomechanics and Geoengineering, vol. 14, no. 3, 2019.

[8] R.-H. Chen, C.-P. Wu, F.-C. Huang, and C.-W. Shen, "Numerical analysis of geocell-reinforced retaining structures," Geotextiles and Geomembranes, vol. 39, pp. 51-62, 2013.

[9] S. N. M. Tafreshi, T. Shaghaghi, G. T. Mehrjardi, A. .R. Dawson, and M. Ghadrdan, "A simplified method for predicting the settlement of circular footings on multi-layered geocell-reinforced non- cohesive soils[J]," Geotextiles and Geomembranes, vol. 43, no. 4, pp. 332-344, 2015.

[10] J. Liu and X. Jia, "Analysis of engineering properties and sensitivity factors of geocell flexible retaining wall based on FLAC3D," Journal of Water Resources and Architectural Engineering, vol. 14, no. 1, pp. 212-217, 2016.

[11] Y. Liu, F. Dai, L. Dong, N. Xu, and P. Feng, "Experimental investigation on the fatigue mechanical properties of intermittently jointed rock models under cyclic uniaxial compression with different loading parameters," Rock Mechanics and Rock Engineering, vol. 51, no. 1, pp. 47-68, 2018a.

[12] Y. Liu, F. Dai, P. Feng, and N. W. Xu, "Mechanical behaviour of intermittent jointed rocks under random cyclic compression with different loading parameters," Soil Dynamics and Earthquake Engineering, vol. 105, pp. 68-82, 2018.

[13] H.-B. Feng, F. Dai, Y. Xu, Z. Yan, and M.-D. Wei, "Mechanical responses and failure mechanism of hydrostatically pressurized rocks under combined compression-shear impacting," International Journal of Mechanical Sciences, vol. 165, Article ID 105219, 2020.

[14] P. Pei, F. Dai, Y. Liu, and M. Wei, "Dynamic tensile behavior of rocks under static pre-tension using the flattened Brazilian disc method," International Journal of Rock Mechanics and Mining Sciences, vol. 126, Article ID 104208, 2020.

[15] R. Jiang, F. Dai, Y. Liu, and A. Li, "Fast marching method for microseismic source location in cavern-containing rockmass: performance analysis and engineering application," Engineering, 2021.

[16] H. Li, Y. Wang, and P. Chen, "Dynamic response analysis of geogrid-reinforced soil retaining walls subjected to seismic load," Highway, vol. 5, pp. 21-26, 2012.

[17] A. Li, Y. Liu, F. Dai, K. Liu, and M. Wei, "Continuum analysis of the structurally controlled displacements for large-scale underground caverns in bedded rock masses," Tunnelling and Underground Space Technology, vol. 97, Article ID 103288, 2020.

[18] H. Lin, D. Lei, R. Yong, C. Jiang, and S. Du, “Analytical and numerical analysis for frost heaving stress distribution within 
rock joints under freezing and thawing cycles," Environmental Earth Sciences, vol. 79, no. 12, p. 305, 2020a.

[19] H. Lin, X. Zhang, R. Cao, and Z. Wen, "Improved nonlinear Burgers shear creep model based on the time-dependent shear strength for rock," Environmental Earth Sciences, vol. 79, no. 6, p. 149, 2020.

[20] Y. Chen, H. Lin, X. Ding, and S. Xie, "Scale effect of shear mechanical properties of non-penetrating horizontal rocklike joints," Environmental Earth Sciences, vol. 80, no. 5, p. 192, 2021.

[21] M. D. Wei, F. Dai, N. W. Xu, T. Zhao, and K. W. Xia, "Experimental and numerical study on the fracture process zone and fracture toughness determination for ISRM-suggested semi-circular bend rock specimen," Engineering Fracture Mechanics, vol. 154, pp. 43-56, 2016.

[22] M.-D. Wei, F. Dai, N.-W. Xu, T. Zhao, and Y. Liu, "An experimental and theoretical assessment of semi-circular bend specimens with chevron and straight-through notches for mode I fracture toughness testing of rocks," International Journal of Rock Mechanics and Mining Sciences, vol. 99, pp. 28-38, 2017.

[23] A. Yang, The Study of Geosynthetics Reinforced Foundation, Hefei University of Technology, Hefei, China, 2007.

[24] D. Li, Dynamic Analysis of High Earth-Rockfill Dam Based on Generalized Plastic Theory Model, Hefei University of Technology, Hefei, China, 2017.

[25] Y. Chen and D. Xu, FLAC/FLAC3D Foundation and Engineering Example, China Water Power Press, Beijing, China, 2013.

[26] T. Liu, The Properties of Geocell Reinforced Wall, Dalian University of Technology, Dalian, China, 2011. 